\title{
Relationship of Flowering Time, Rate of Seed Germination, and Time of Leaf Budbreak and Usefulness in Selecting for Late-flowering Apples
}

\author{
Shawn A. Mehlenbacher \\ Department of Horticulture, Oregon State University, Corvallis, OR 97331 \\ Anna M. Voordeckers \\ Rutgers Fruit Research and Development Center R.D. 2, Box 38, Cream Ridge, NJ 08514 \\ Additional index words. Malus $\times$ dornestica, chilling requirement, spring frost, fruit breeding
}

\begin{abstract}
The relationship between dormancy of seeds and buds of apple (Malus $\times$ domestica Borkh.) might provide breeders with an early opportunity to select for delayed development. Seeds of late-flowering genotypes require much longer exposure to chilling temperatures than those of early flowering" genotypes, and they germinate over a much longer period. In three progenies that exhibit much variation for the two traits, seed germination time was correlated with time of leafing-out of the resulting seedlings, and could be used to select for delayed budbreak. However, selection would be ineffective when little genetic variation for seed germination and budbreak is present. Leafing-out ratings in the nursery in the 2nd year were highly correlated with those in the 3rd year, indicating that selection for late leafing in the nursery during the 2 nd year would be more effective than selection based on seed dormancy, especially in progenies exhibiting little genetic variability for this trait. Breeders can effectively use both relationships by first eliminating early germinating seeds and then eliminating early leafing seedlings.
\end{abstract}

Spring frost is a major factor that limits the areas in which temperate zone deciduous tree fruits can be grown and is responsible for much of the year-to-year fluctuations in yield. To minimize frost injury, fruit growers often invest considerable sums of money in wind machines, sprinkler-irrigation, and heaters. Trees are most sensitive to frost when in full bloom, and since the probability of frost is largely a function of calendar date, late-flowering selections often avoid injury. In apple, genotypes are known that vary in flowering date by $>30$ days. The latest blooming genotypes, cider apples from Europe (Murawski, 1967; Tydeman, 1958), bloom 3 weeks later than 'Delicious'. These cultivars have higher chilling requirements and higher heat requirements in the post-rest phase (Gianfaga and Mehlenbacher, 1985; Swartz and Powell, 1981). Their use is currently limited because of their unattractive appearance, poor fruit quality, and susceptibility to fire blight [Erwinia amylovora (Burrill) Winslow] (Aldwinkle et al., 1976). However, they represent very valuable germplasm that breeders can use in the development of late-flowering selections with improved fruit quality and disease resistance. This has been one of the objectives of the apple breeding program at Rutgers Univ. since 1955.

As part of this continuing effort, crosses were made in 1984 between late-flowering genotypes and selections resistant to apple scab and fire blight. Date of leafing-out of juvenile seedlings was shown by Tydeman (1964) to be highly correlated with flowering date in the adult trees, and elimination of early leafing seedlings in the nursery during the second season of growth (15 months after seed germination) was very effective in delaying bloom date in the seedling population (Murawski, 1967). A similar strategy has been used at Rutgers. During stratification, it was noted that seeds of the 1984 crosses involving late-blooming parents, compared with crosses between selections flowering at the normal time, not only germinated later but they also germinated over a much longer time. Previous studies have

Received for publication 29 Oct. 1990. Oregon Agricultural Experiment Station Technical Paper no. 9413. The cost of publishing this paper was defrayed in part by the payment of page charges. Under postal regulations, this paper therefore must be hereby marked advertisement solely to indicate this fact. demonstrated that buds and seeds of apple (Pasternak-Orawiec and Powell, 1983) and pear (Westwood and Bjornstad, 1968) have similar chilling requirements, and suggested that selection for late seed germination during stratification might be an effective way of indirectly selecting for delayed leaf budbreak in the resulting seedlings. Experiments were conducted in 19851989 to further investigate the relationships among bloom date of the parents, seed stratification time, and date of leafing-out of seedlings, and to determine the most effective way for apple breeders to select for delayed flowering in segregating progenies.

\section{Materials and Methods}

Flowering date and rate of seed germination (Expt. 1). The relationship between flowering date of apple genotypes and the rate of germination of their open-pollinated seeds was investigated. Seeds were harvested from mature fruit of 22 genotypes in the Rutgers apple collection that exhibit a range in bloom date of $\approx 1$ month. Seeds were dried and stored at room temperature (20C) until the start of the experiment, when they were rolled in paper towels and soaked in distilled water for $48 \mathrm{~h}$. The imbibed seeds were then dipped in ethyl alcohol for 5 see, followed by $0.5 \%$ sodium hypochlorite (10\% Chlorox) for 5 rein, and a saturated suspension of Benlate and Captan fungicides for $10 \mathrm{sec}$. Seeds were then placed in petri dishes between layers of moist filter paper and held at 4C. Dishes were inspected and germinated seeds (i.e., those with radicles emerged) removed and counted at weekly intervals. About 60 seeds of each genotype were included in each of four replications. Seeds of the first replication were placed in dishes on 27 Nov. 1985. Replications two to four were initiated 1 to 3 weeks later, respectively. The experiment was terminated after 67 weeks when only few seeds remained. At that time, the dishes were moved to room temperature and seeds that failed to germinate were considered dead. For each genotype in each replication, the number of weeks required for each of the following germination percentages was calculated: first seed germinated, $25 \%$ germination, $50 \%$ germination, $75 \%$ germination, and last seed germinated (i.e., $100 \%$ germination). The number of weeks required 
for each event was then averaged over replications. Flowering dates were recorded in 1986 as the date on which king flowers were open and other flowers were at the balloon stage, and are expressed in Table 1 relative to 'Delicious (Redchief Campbell)'. Correlation coefficients were calculated for date of flowering of the parent tree and the average number of weeks required to reach these five germination percentages.

Rate of seed germination and time of budbreak (Expt. 2). The

Table 1. Bloom time and average number of weeks for various germination percentages of 22 apple genotypes (Expt. 1).

\begin{tabular}{lrrrrrr}
\hline \hline & & \multicolumn{5}{c}{$\begin{array}{c}\text { Average no. of weeks for a given } \\
\text { germination }\end{array}$} \\
\cline { 3 - 7 } Genotype & $\begin{array}{c}\text { Bloom } \\
\text { time }\end{array}$ & Initial & $25 \%$ & $50 \%$ & $75 \%$ & $100 \%$ \\
\hline NJ45 & -6 & 13.0 & 14.3 & 15.0 & 16.0 & 19.0 \\
A9-183 & -5 & 11.3 & 13.5 & 14.5 & 15.4 & 20.0 \\
Maribor 2439 & -5 & 13.8 & 15.5 & 16.3 & 16.9 & 18.8 \\
A10-115 & -4 & 13.0 & 16.3 & 17.0 & 17.8 & 27.5 \\
D98-188 & -4 & 14.5 & 16.3 & 17.0 & 17.8 & 21.5 \\
McIntosh & -3 & 12.3 & 14.3 & 15.1 & 16.0 & 18.5 \\
Empire & -2 & 12.8 & 14.8 & 15.3 & 16.3 & 18.8 \\
Delicious (Redchief) & 0 & 12.5 & 14.0 & 15.3 & 16.3 & 18.8 \\
Golden Delicious & +3 & 13.3 & 15.0 & 16.0 & 17.2 & 18.5 \\
Rome Beauty & +6 & 15.5 & 17.5 & 18.5 & 19.8 & 23.5 \\
Jonagram & +7 & 15.0 & 16.9 & 18.0 & 19.0 & 24.5 \\
D101-360 & +8 & 14.3 & 16.3 & 17.5 & 19.3 & 27.0 \\
D6-96 & +8 & 16.0 & 18.0 & 20.0 & 22.5 & 31.5 \\
NJ 126 & +9 & 15.0 & 17.3 & 18.8 & 20.1 & 33.8 \\
NJ 131 & +11 & 14.3 & 17.4 & 18.6 & 21.5 & 46.3 \\
Red Bellflower & +12 & 14.0 & 17.1 & 18.8 & 22.0 & 36.8 \\
D94-337 & +13 & 16.0 & 19.4 & 22.5 & 26.6 & 35.8 \\
NJ 140 & +15 & 15.8 & 19.3 & 25.0 & 31.8 & 50.5 \\
Camuzat & +18 & 17.3 & 24.2 & 28.0 & 31.3 & 40.0 \\
NJ 136 & +18 & 18.8 & 23.0 & 30.4 & 39.3 & 56.3 \\
Spätblühender & +20 & 19.0 & 31.1 & 35.0 & 40.0 & 55.3 \\
NJ 137 & +20 & 18.3 & 27.4 & 35.3 & 42.8 & 63.8 \\
\hline Average & & & & & & \\
\hline
\end{tabular}

${ }^{\mathrm{z}}$ Average of four replications of $\approx 60$ seeds each.

'B1eom time in days before $(-)$ or after ( + ) 'Delicious' (1986).

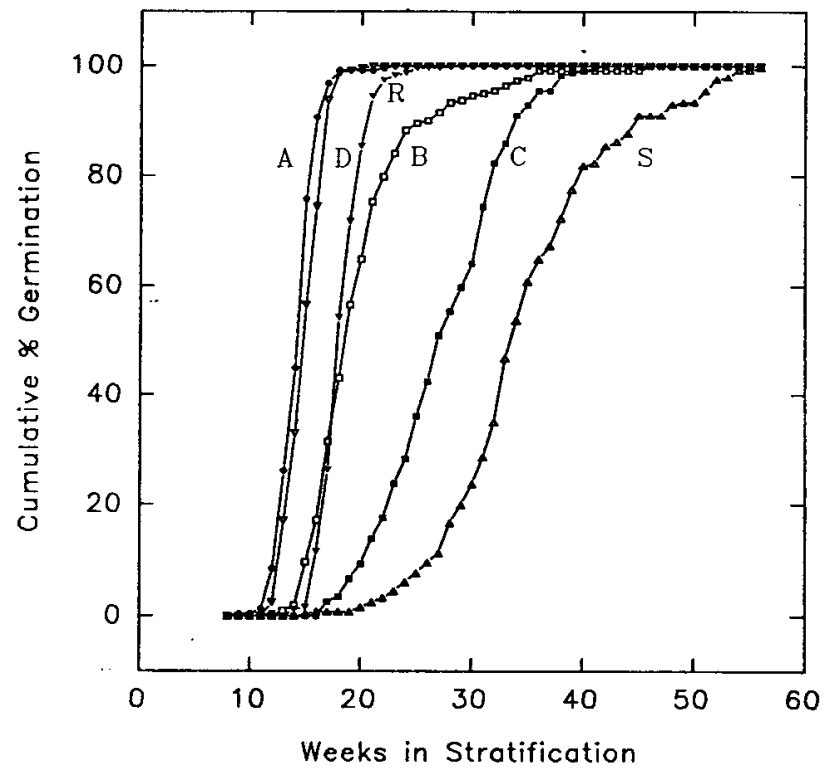

Fig. 1. Cumulative seed germination percentage of six apple genotypes as a function of time (weeks) in stratification at 4C. At $80 \%$ germination, curves from left to right are for A9-183 (A), Delicious (D), Rome Beauty (R), Red Bellflower (B), Camuzat (C), and Spätblühender (S) (Expt. 1). relationship between time of seed germination in stratification and time of leaf budbreak of the resulting seedlings was studied. Seeds of three progenies expected to segregate for these two traits were imbibed and placed in petri dishes in late Oct. 1986 as described for Expt. 1. Germinated seeds were removed from stratification and planted in flats in the greenhouse on four dates in 1987 (30 Jan., 20 Feb., 13 Mar., and 3 Apr). When 15 to $30 \mathrm{~cm}$ tall, seedlings were transplanted to a field nursery in a split-plot design. There were three replications, with progenies as main plots and germination dates as subplots. Extra seedlings and those from additional progenies were planted in adjacent rows. Degree of bud growth was noted on six dates in 1988 (17 Mar., 30 Mar., 15 Apr., 26 Apr., 3 May, and 16 May) and four dates in 1989 (8, 15, and 23 Apr., and 1 May). Rating was done on a scale of $1=$ no bud development, $2=$ green tip visible at terminal bud, $3=$ green tips visible at terminal and lateral buds, and 4, 5, and 6 for small, medium $(3 \mathrm{~cm}$ long), and large ( $5 \mathrm{~cm}$ long) leaves, respectively. Average ratings were calculated for each seedling in each year, and for the 2 years. An analysis of variance was performed for average bud growth ratings averaged over the 2 years. Correlation coefficients were calculated to determine the consistency of bud growth ratings over the 2 years, and to determine the extent to which seed germination and budbreak were related.

\section{Results}

Expt. 1. Seeds of late-blooming genotypes required a longer stratification time and germinated over a much longer period than those of early flowering genotypes (Table 1, Fig. 1). Bloom date and time to $50 \%$ germination were highly correlated $(r=$ $0.85)$, indicating a close relationship between bloom date of the female parent and chilling requirement of the seeds (Table 2). As these were open-pollinated seeds, the pollen parent would be a mixture of genotypes with roughly the same flowering time as the seed parent. Measures of variability in seed germination rate are provided by both the range and the interquartile range. The range was lowest ( 5 weeks) for the early blooming selection Maribor 2439 and highest (46 weeks) for the very late-blooming

Table 2. Correlation coefficients for bloom date of 22 apple genotypes and germination rate of their open-pollinated seeds in stratification at 4C (Expt. 1). All are significant at $P=0.01$.

\begin{tabular}{lccccc}
\hline & \multicolumn{5}{c}{$\begin{array}{c}\text { Average no. of weeks for a given } \\
\text { germination percentage }\end{array}$} \\
\cline { 2 - 6 } & Initial & $25 \%$ & $50 \%$ & $75 \%$ & $100 \%$ \\
\hline $\begin{array}{l}\text { Flowering date } \\
\text { Weeks to germination }\end{array}$ & 0.87 & 0.83 & 0.86 & 0.87 & 0.88 \\
$\begin{array}{l}\text { percentage } \\
\text { Initial }\end{array}$ & & & & \\
$25 \%$ & 0.92 & 0.93 & 0.92 & 0.83 \\
$50 \%$ & & & 0.98 & 0.94 & 0.86 \\
$75 \%$ & & & & 0.99 & 0.91 \\
\hline
\end{tabular}

Table 3. Analysis of variance for apple budbreak ratings (average ratings for three progenies and 2 years) (Expt. 2).

\begin{tabular}{lrcrr}
\hline \hline Source & df & Mean square & F value & $P$ \\
\hline Replications & 2 & 0.13 & 0.64 & \\
Progenies & 2 & 1.45 & 7.04 & 0.05 \\
Main plot error & 4 & 0.21 & & \\
Seed germination dates & 3 & 2.17 & 19.85 & 0.00 \\
Progenies $\times$ dates & 6 & 0.12 & 1.05 & 0.43 \\
Subplot error & 18 & 0.11 & & \\
\hline
\end{tabular}


Table 4. Correlation coefficients for time of apple seed germination and leaf rating in 1988 and 1989 (Expt. 2).

\begin{tabular}{|c|c|c|c|c|c|}
\hline \multirow[b]{3}{*}{ Progeny } & \multirow{3}{*}{$\begin{array}{l}\text { Seedlings } \\
\text { (no.) }\end{array}$} & \multicolumn{4}{|c|}{ Correlation coefficients for germination dates and leaf ratings } \\
\hline & & \multicolumn{3}{|c|}{ Germ. date and rating } & \multirow{2}{*}{$\begin{array}{c}\text { Rating } \\
\text { (1988 and 1989) }\end{array}$} \\
\hline & & 1988 & 1989 & Mean $^{y}$ & \\
\hline NJ133 x Coop 31 & 125 & -0.25 & -0.26 & -0.26 & +0.84 \\
\hline $\mathrm{D} 101-360 \times \mathrm{D} 1-32$ & 134 & -0.40 & -0.36 & -0.39 & +0.85 \\
\hline $\mathrm{D} 1-32 \times \mathrm{D} 101-360$ & 308 & -0.59 & -0.65 & -0.66 & +0.79 \\
\hline \multicolumn{6}{|l|}{ Pooled } \\
\hline (three progenies) ${ }^{\mathrm{x}}$ & 567 & -0.50 & -0.53 & -0.54 & +0.85 \\
\hline \multicolumn{6}{|l|}{ Pooled } \\
\hline (nine progenies) ${ }^{\mathrm{w}}$ & 1063 & -0.39 & -0.39 & -0.43 & +0.95 \\
\hline
\end{tabular}

${ }^{2}$ A negative correlation coefficient between seed germination date and leaf budbreak rating indicates that later germinating seeds produced seedlings with lower ratings (i.e., they leafed out later).

'Mean of 1988 and 1989 ratings.

${ }^{x}$ Total of the three progenies listed above.

"Includes an additional 496 seedlings from six progenies whose parents flower about the same time as 'Delicious'.

selection NJ 137. The interquartile range, the number of weeks from $25 \%$ to $75 \%$ germination, was $<2$ weeks for early blooming selections and $>10$ weeks for late-blooming selections.

Expt. 2. Differences among progenies for average budbreak ratings were just significant at $P=0.05$ (Table 3), with seedlings of the cross NJ $133 \times$ Coop 31 leafing out earlier than the other two progenies, which were reciprocal crosses. Large differences were detected among germination dates. No differences were detected among replications, so seedlings in all replications and adjacent rows were pooled to study the correlation between seed germination and budbreak of the resulting seedlings (Table 4). The correlation coefficient between seed germination date and mean leaf break rating was highest $(r=$ $-0.66)$ in the cross of D1-32 $\times$ D101-36O, two selections that bloom 11 and 8 days after 'Delicious', respectively, and in which a wide range in seed germination and date of leafing-out was apparent. Correlation coefficients are negative, as later leafing seedlings have lower leaf budbreak ratings. Histograms illustrate the relationship in the cross D1-32 $\times$ D101-36O (Fig. 2 ). We cannot explain why seeds of this cross germinated later and seedlings leafed out later than those of the reciprocal cross. The correlation coefficient was lower $(r=-0.26)$ for the cross of selection $\mathrm{NJ} 133 \times$ Coop 31, which flower 13 and 0 days after 'Delicious', respectively. In six other progenies between parents flowering with the major apple cultivars, the relationship was less striking. In these seed lots, both germination and budbreak of the seedlings occurred over a shorter period and, consequently, correlation coefficients were lower. It appears from these data that indirect selection for late budbreak by selecting seeds with a high chilling requirement would be effective in progenies exhibiting a wide range for both characters, but not in progenies segregating for a narrow range of expression for these traits.

For the three progenies studied, budbreak ratings in 1988 and 1989 were highly correlated $(r=0.79$ to 0.85$)$. Pooled data from nine progenies over 2 years of evaluation showed a correlation coefficient of 0.95 , consistent with the very high coefficients calculated by Tydeman (1964).

\section{Discussion}

Tydeman (1964) and Murawski (1967) showed that in a collection of apple cultivars and selections differing widely in time of flowering, leaf break ratings and date of full bloom are highly correlated in apple ( $r=0.98$ and 0.70 , respectively) and that time of vegetative budbreak of juvenile seedlings can be used effectively to select for late flowering. Early leafing seedlings are generally eliminated as they leaf out in the 2nd year, 15 months after seed germination (Murawski, 1967). In segregating progenies, time of leaf budbreak exhibits a continuous distribution, indicating control by several genes. The average budbreak ratings of the parents provide a good predictor of progeny performance (Tydeman, 1963). Neither Tydeman (1963) nor Murawski (1967) mentioned delayed seed germination in their crosses. The results of our study indicate that selection based on time of seed germination also can be used to select for delayed budbreak in progenies exhibiting large variance for these traits, but not when variability is limited. In all cases, selection based on seed germination was less effective than directly selecting for delayed budbreak $(r=-0.54$ vs. $r=0.85)$. Combined selection appears to be the most effective method. This strategy involves producing large numbers of progenies segregating for late budbreak, stratifying the seeds under uniform conditions and eliminating those $(30 \%)$ that germinate most rapidly, planting the remaining seeds and transplanting the resulting seedlings to a field nursery, and selecting the following spring for late budbreak. Only late-leafing seedlings would be grown to fruiting. This procedure would allow the breeder to efficiently handle large numbers of progenies, seeds, and seedlings.

A great deal of variability exists within the cultivated apple for time of budbreak and flowering, allowing breeders to select for genotypes adapted to local conditions. The "delayed dormancy" associated with inadequate chilling has not been observed on late-flowering apple cultivars in New Jersey or Oregon. In these and other areas with high annual accumulations of chilling hours, late-flowering cultivars that avoid spring frost would allow more regular production at reduced cost. Until now, poor appearance and quality have been serious obstacles to commercial use of this germplasm. Twenty-five years of apple breeding at Rutgers Univ. has successfully combined late flowering with vastly improved fruit quality and appearance, and these selections are less susceptible to fire blight than their late-flowering ancestors. Sixteen such selections are currently being tested, and descriptions and pedigrees of these selections are available from the authors.

In contrast to pear, where variation in seed germination and time of flowering is primarily among species (Faust et al., 1976; 

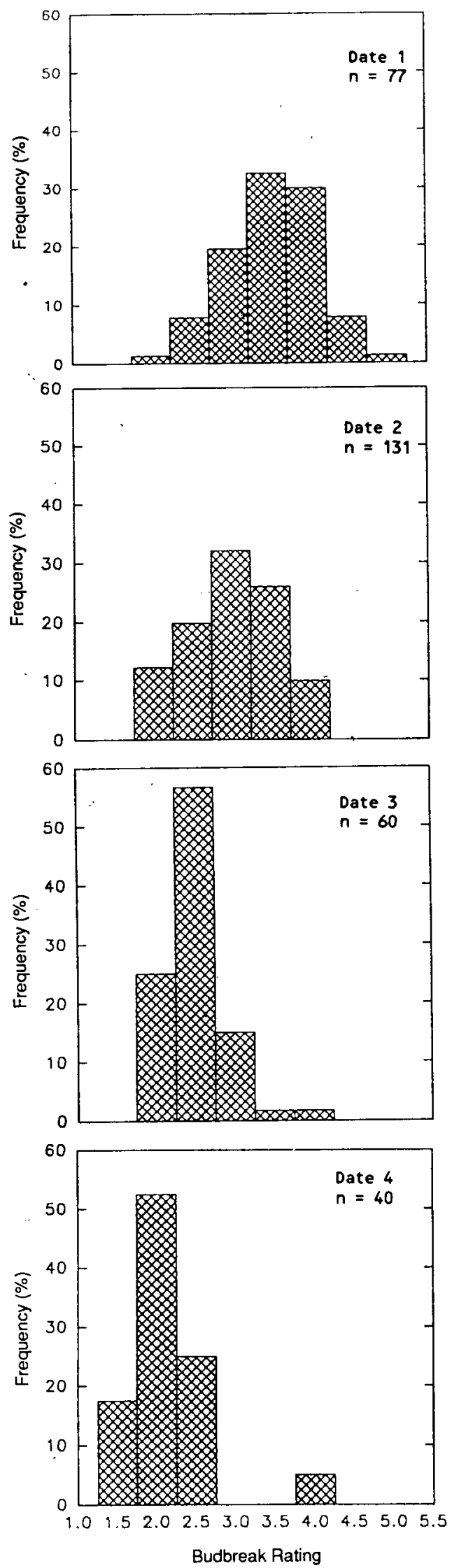

Westwood and Bjornstad, 1968), this variation in apple exists within one species, Malus $\times$ domestics. All of the cultivars and selections used in this study are regular diploids, and there have been no barriers to combining late flowering with improved fruit quality.

Variability in rate of seed germination maybe due in part to factors not investigated in this study. Maternal effects such as seed coat thickness and concentration of germination inhibitors may be present. Also not investigated in this study is the possibility that different seed lots have different optimum temperatures for stratification. Alternating moderate and low temperatures would also clearly affect the rate of seed germination, but we found no reports investigating such treatments.

\section{Literature Cited}

Aldwinkle, H. S., R.D. Way, K.G. Liverrnore, J.L. Preczewski, and S.V. Beer. 1976. Fire blight in the Geneva apple collection. Fruit Var. J. 30:42-55.

Faust, M., R. Zimmerman, and T. van der Zwet. 1976. Genetic transmission of bloom date in pears. HortScience 11:59-60.

Gianfagna, T.J. and S.A. Mehlenbacher. 1985. Importance of heat requirement for bud break and time of flowering in apple. HortScience 20:909-911.

Murawski, H.J. 1967. Contributions to research on apple breeding. X. Results from the breeding of apple varieties with late leaf bud expansion and flowering. Der Ziichter 37:134-139.

Pasternak-Orawiec, G. and L.E. Powell. 1983. Changes in abscisic acid and gibberellin during the stratification of low and high chilling apple seeds. HortScience 18:560. (Abstr.)

Swartz, H.J. and L.E. Powell. 1981. The effect of long chilling requirement on time of bud break in apple. Acts Hort. 120:173-178.

Tydeman, H.M. 1958. The breeding of late flowering apple varieties. Rpt. E. Malling Res. Sta. 1957:68-73.

Tydeman, H.M. 1963. The inheritance of time of leaf bud break and leaf fall in seedling apples. Rpt. E. Mailing Res. Sta. 1962:58-63.

Tydeman, H.M. 1964. The relation between time of leaf break and of flowering in seedling apples. Rpt. E. Mailing Res. Sta. 1963:7072 .

Westwood, M.N. and H.O. Bjornstad. 1968. Chilling requirements of dormant seeds of 14 pear species as related to their climatic adaptation. Proc. Amer. Soc. Hort. Sci. 92:141-149.
Fig. 2. Histogram of budbreak ratings as a function of time of apple seed germination in the cross D1-32 $\times$ D101-36O. Budbreak ratings of seedlings range from 1 (no bud development) to 6 (large leaves) and are averaged over six dates in 1988 and four dates in 1989. The bar for rating 1.5 represents the frequency of seedlings with average ratings from 1.01 to 1.50 . The top histogram is for the first seeds to germinate (planting date $30 \mathrm{Jan}$.) and the bottom histogram is for the last seeds to germinate (planting date 3 Apr.). Note that lategerminating seeds (dates 3 and 4 ) produced seedlings that leafed out later (had lower budbreak ratings) (Expt. 2). 